www.jmscr.igmpublication.org

Impact Factor (SJIF): 6.379

Index Copernicus Value: 79.54

ISSN (e)-2347-176x ISSN (p) 2455-0450

crossrefDOI: https://dx.doi.org/10.18535/jmscr/v6i10.90

Journal Of Medical Science And Clinical Research

\title{
Benefits of Transdermal Nitroglycerine Patch in the Prevention of Preterm Labour
}

Authors

\section{Prof. Dr Latha.K ${ }^{1^{*}}$, Dr Jayashree. ${ }^{2}$, Dr Kousalya Devi.A ${ }^{3}$}

${ }^{1}$ Professor, Department of Obstetrics and Gynaecology, Rajah Muthiah Medical College, Annamalai University, Chidambaram

${ }^{2}$ Associate Professor, Department of Obstetrics and Gynaecology, Rajah Muthiah Medical College,

Annamalai University, Chidambaram

${ }^{3}$ Final Year Post Graduate, Department of Obstetrics and Gynaecology, Rajah Muthiah Medical College,

Annamalai University, Chidambaram

*Corresponding Author

Prof. Dr Latha.K

Professor, Department of Obstetrics and Gynaecology, Rajah Muthiah Medical College, Annamalai University, Chidambaram

Email: sekar_2010@yahoo.in

\begin{abstract}
Preterm birth is delivery before 37 completed weeks. Majority of complications occur before 33 weeks. Preterm labour remains as enigma in obstetrics even today. The need of today is to select the best to colytic agent with benefit. The study aims to found the benefits of transdermal nitroglycerine patch in prevention of preterm labour.
\end{abstract}

Method: study conducted in department of obstetrics and gynaecology, Rajah Muthiah Medical College and Hospital, Chidambaram. A prospective randomized study of 80 women of preterm labour was enrolled after informed consent from them. Patients were given transdermal NTG patch as tocolytic agent. According to study protocol.

Result: 1) Successful tocolytic was observed in majority of women (66.2\%). 2) Side effect was also less in NTG.

Conclusion: This randomized prospective study supports to use of NTG patch in case of safety, effectiveness, cost effective and it is non invasive method of tocolysis.

Keywords: Dermal nitroglycerine patch tocolysis (NTG 10).

\section{Introduction}

Preterm labour is defined by WHO as onset of labour prior to completion of 37 weeks in a pregnancy beyond 20 weeks of gestation. ${ }^{2}$ The period of viability varies in different countries from 20 to 28 weeks. Preterm labour is considered $^{13}$ to be established if regular uterine contractions can be documented for atleast 4 in 20 minutes or 8 in 60 minutes with progressive change in cervical score in the form of $80 \%$ or more, cervical dilatation of $>1 \mathrm{~cm}$. Half of neonatal morbidity occurs in preterm infants. ${ }^{3}$ Inspite of all major advances in obstetrics and neonatal care ${ }^{14}$, there has been no decrease in 
incidence of preterm labour over half a century. Preterm birth ${ }^{15}$ occurs in $5-12 \%$ of all pregnancy and accounts for majority of neonatal death and nearly half of all cases of congenital neurological disability $^{1}$ including cerebral palsy. Organic nitrates are rapidly denitrated enzymatically in smooth muscle cell to release nitric oxide which activates guanyl cyclase thereby increase CGMP which causes dephosphorylation ${ }^{4}$ of myosin light chain kinase. Reduced availability of phosphorylated MLCK interfere with activation of myosin. It fails to interact with actin to cause contraction. Consequently relaxation occurs. Raised intracellular CGMP $^{5}$ may also reduce calcium entry contributes to relaxation. Transdermal NTG part containing 25mg (TTS-5), 50mg (TTS-10) and 75mg (TTS-15) are available for us. TTS 10 denotes normal amount of nitroglycerine in $\mathrm{mg}$ delivered/24 hours. When NTG content is $50 \mathrm{mg}$, rate of drug release per hour is $0.4 \mathrm{mg}$.

\section{Aim}

The aim of study is to evaluate the effect and safety of transdermal nitroglycerin in tocolysis and effect of maternal outcome.

\section{Objective}

The objective of study is to evaluate the use of transdermal nitroglycerin in treatment of preterm labour in terms of

1) Subsidence of uterine contractions

2) Prolongation of pregnancy

3) Maternal side effects

\section{Materials and Method}

This study is done during the period of November 2016 to October 2018, in obstetrics and gynaecology, who are diagnosed to have preterm labour, in Rajah Muthiah Medical College and Hospital, Chiambaram.

\section{Sample Size}

A total of 80 pregnant women of age above 18 years

\section{Inclusion Criteria}

1. Patient was having preterm labour aged 18 years and above giving valid informed consent

2. Gestational age between 28 to 34 weeks

3. 2 uterine contractions in 10 minute period each lasting for 20 seconds

4. Progressive cervix effacement upto $75 \%$

5. Cervix dilatation upto $3 \mathrm{~cm}$

6. Patient with intact membranes.

\section{Exclusion Criteria:}

1. High risk pregnancy, multiple gestation, cardiac disease, PIH, previous caeserian section, renal disease and pulmonary diseases

2. Fetuses with fetal distress, IUGR, congenital anomalies.

3. Polyhydramnios, oligohydramnios, erythroblastosis

4. Age $<18$ years

\section{Method}

Written consent was obtained from all patients after the drug administration done. Patient with preterm labour with gestational age $<34$ weeks were given Inj. bethamethasone $12 \mathrm{mg}$ i.m 2 doses 24 hours apart to improve lung maturity. Every patient with preterm labour pain was given Inj. buscopan i.m stat done to exclude false labour pain and oral Amox 500mg TDS and T.metro 400mg TDS for 5 days as antibiotic prophylaxis against subclinical infection. If the patient was stable and no abdominal pain, discharge with advice to review every week.

\section{Treatment protocol of NTG patch in preterm labour}

An NTG patch of 50mg (NTG-10) releasing at steady rate of $0.4 \mathrm{mg} /$ hour, total dose released $10 \mathrm{mg} / 24$ hours, applied in abdomen and monitored for uterine contractions, if unchanged or increased second NTG 10mg patch applied, even after that pain persist, conventional tocolysis. Followed if pain decreased or subside both NTG 10 will be continued for 24 hours. After 24 hours 
replaced by same number of patches, after completion of 48 hours all patches are removed.

\section{Analysis of Data}

To calculate nominal data, simple percentage used. Mean and SD were used to describe nearly distributed quantitative data from subjects. Software used for analysing data SPSS 21. Treatment was successful if there was no uterine contractions, no progression in cervical changes, completion in steroid course and also if contractions did not occur again within 2 days of stoppage of therapy. Treatment was deemed failure, if uterine relaxation does not occur, steroid dose was not achieved even after using maximum NTG dose of significant side effects developed that needs termination of therapy.

\section{Results}

Table 1- shows GA at presentation, majority had GA at time of presentation $32-34$ weeks $(\mathrm{N}=52$, $67 \%), 26.2 \%(\mathrm{~N}=2)$ belongs to GA 30-32 weeks. only $8.8(\mathrm{~N}=7)$ had GA $28-30$ weeks. $40 \%$ women had cervix effacement $50 \%(\mathrm{~N}=32)$ $38.8 \%$ women had cervix effacement $25 \%(\mathrm{~N}=31)$ $21.1 \%$ had cervix effacement $75 \%(\mathrm{~N}=17)$
Most of study women had cervical dilatation of $2.3 \mathrm{~cm}(\mathrm{~N}=59,73.8 \%)$, only $26.2 \%(\mathrm{~N}=21)$ had cervical dilatation of $<2 \mathrm{~cm}$.

The common duration of prolongation was 2 to 7 days in which $38.8 \% \quad(\mathrm{~N}=31)$ was observed. Prolongation <2 days was observed in $33.7 \%$ ( $\mathrm{N}=27)$, prolongation was $7-14$ days for $16.3 \%$ $(\mathrm{N}=13)$ and $14 \quad-21$ days for $8.8 \% \quad(\mathrm{~N}=7)$, prolongation of $>21$ days was observed in $2.4 \%$ $(\mathrm{N}=2)$

Successful of, $<48$ hours is 27 numbers; percentage- $33.8 \%$, in $>48$ hours is 53 numbers; percentage- $66.2 \%$. the success create tocolysis was $66.2 \%(\mathrm{~N}=53)$

Prolongation of pregnancy for 36 weeks + above was $8.7 \%(\mathrm{~N}=7)$ whereas most of the women had gestational age $<36$ weeks $(\mathrm{N}=73,91.3 \%)$ at the time of delivery.

Headache was the common maternal complication $(\mathrm{N}=17) 21.3 \%$, followed by dizziness $(\mathrm{N}=7$, $8.8 \%$ ), majority of study had no maternal complications $(\mathrm{N}=53,60.2 \%)$

Table: 1 Gestational Age at Presentation

\begin{tabular}{|l|c|c|}
\hline G.A (Weeks) & Number & Percentage \\
\hline $28-30$ & 7 & 8.8 \\
\hline $30-32$ & 21 & 26.2 \\
\hline $32-34$ & 52 & 65.0 \\
\hline Total & 80 & 100 \\
\hline
\end{tabular}

\section{Cervical Dilatation}

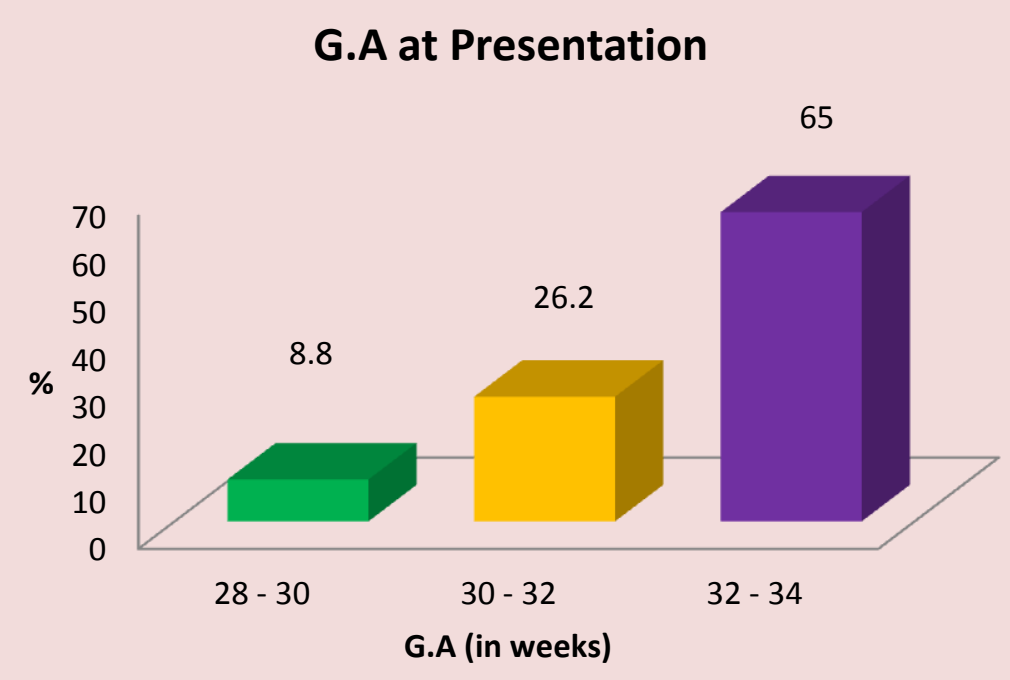

Hajority of the study women had gestational age at the time of presentation was 32-34 weeks $(\mathrm{N}=$ $52,65 \%)$. Gestational age of 30 to 32 weeks was observed in $26.2 \%$ of the women $(\mathrm{N}=21)$ only $8.8 \%(\mathrm{~N}=7)$ of the women had gestational age of 28-30 weeks. 


\section{JMSCR Vol||06||Issue||10||Page 533-539||October}

Table: 2 Cervical Effacement

\begin{tabular}{|l|c|c|}
\hline Cervical Effacement & Number & Percentage \\
\hline $25 \%$ & 31 & 38.8 \\
\hline $50 \%$ & 32 & 40.0 \\
\hline $75 \%$ & 17 & 21.2 \\
\hline Total & 80 & 100 \\
\hline
\end{tabular}

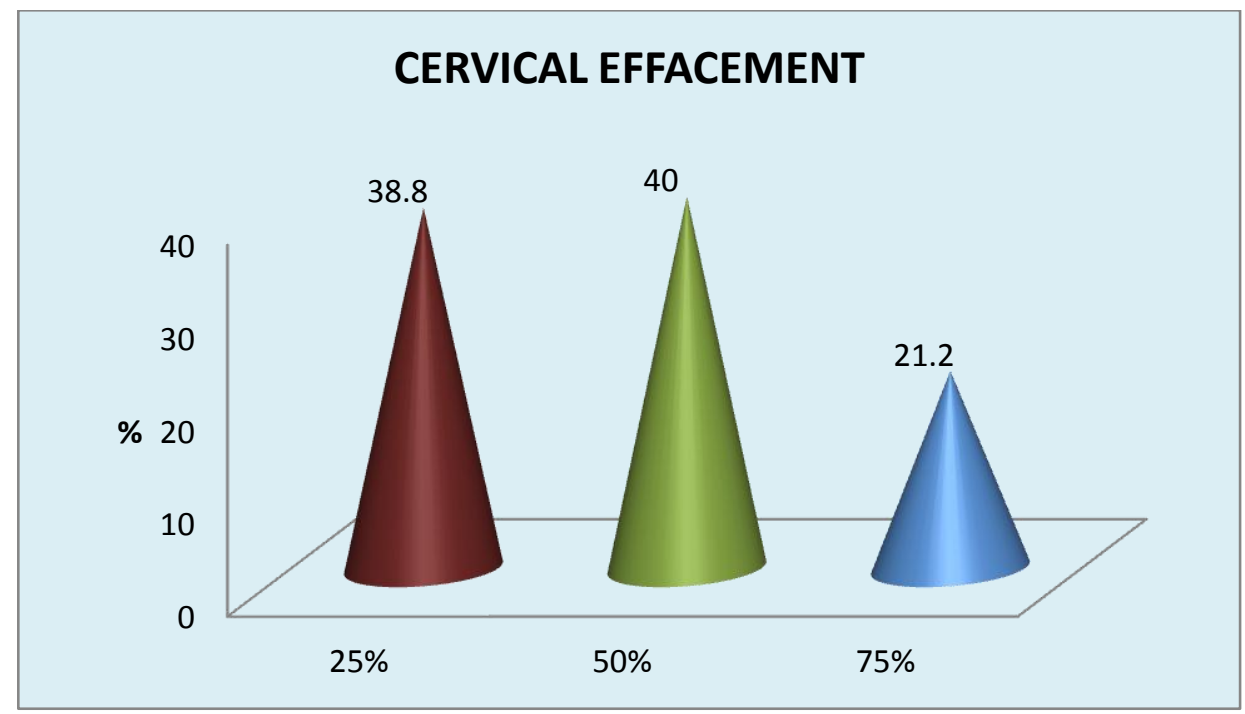

$50 \%$ cervical effacement was the feature of $40 \%$ $(\mathrm{N}=32)$ of the study women $38.8 \%(\mathrm{~N}=31)$ of the women had $25 \%$ cervical effacement $75 \%$ cervical effacement was found in $21.2 \%(\mathrm{~N}=17)$ of the women.

Table: 3 Cervical Dilatation

\begin{tabular}{|l|c|c|}
\hline Cervical Dilation & Number & Percentage \\
\hline$<2 \mathrm{~cm}$ & 21 & 26.2 \\
\hline $2-3 \mathrm{~cm}$ & 59 & 73.8 \\
\hline Total & 80 & 100 \\
\hline
\end{tabular}

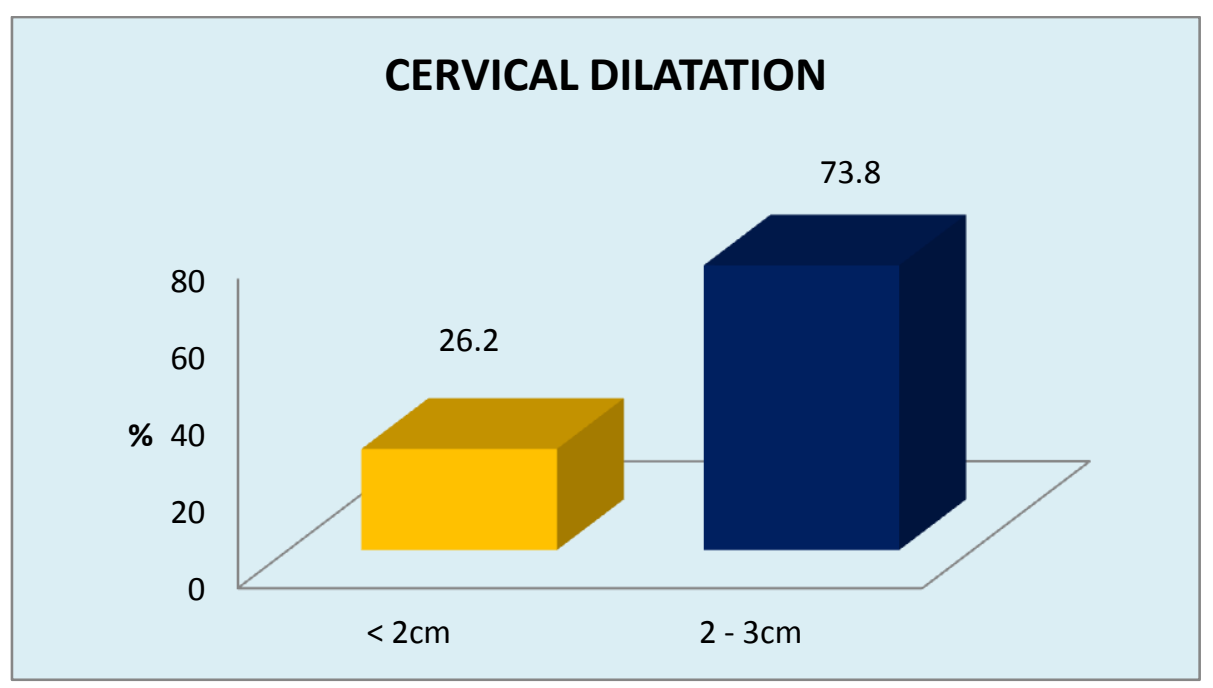

Most of the study women had cervical dilatation of $2-3 \mathrm{~cm}(\mathrm{~N}=59,73.8 \%)$ only $26.2 \%(\mathrm{~N}=21)$ had cervical dilatation of $<2 \mathrm{~cm}$. 
Table: 4 Duration of Prolongation

\begin{tabular}{|l|c|c|}
\hline Duration of Prolongation & Number & Percentage \\
\hline$<2$ days & 27 & 33.7 \\
\hline $2-7$ days & 31 & 38.8 \\
\hline $7-14$ days & 13 & 16.3 \\
\hline $14-21$ days & 7 & 8.8 \\
\hline$>21$ days & 2 & 2.4 \\
\hline Total & 80 & 100 \\
\hline
\end{tabular}

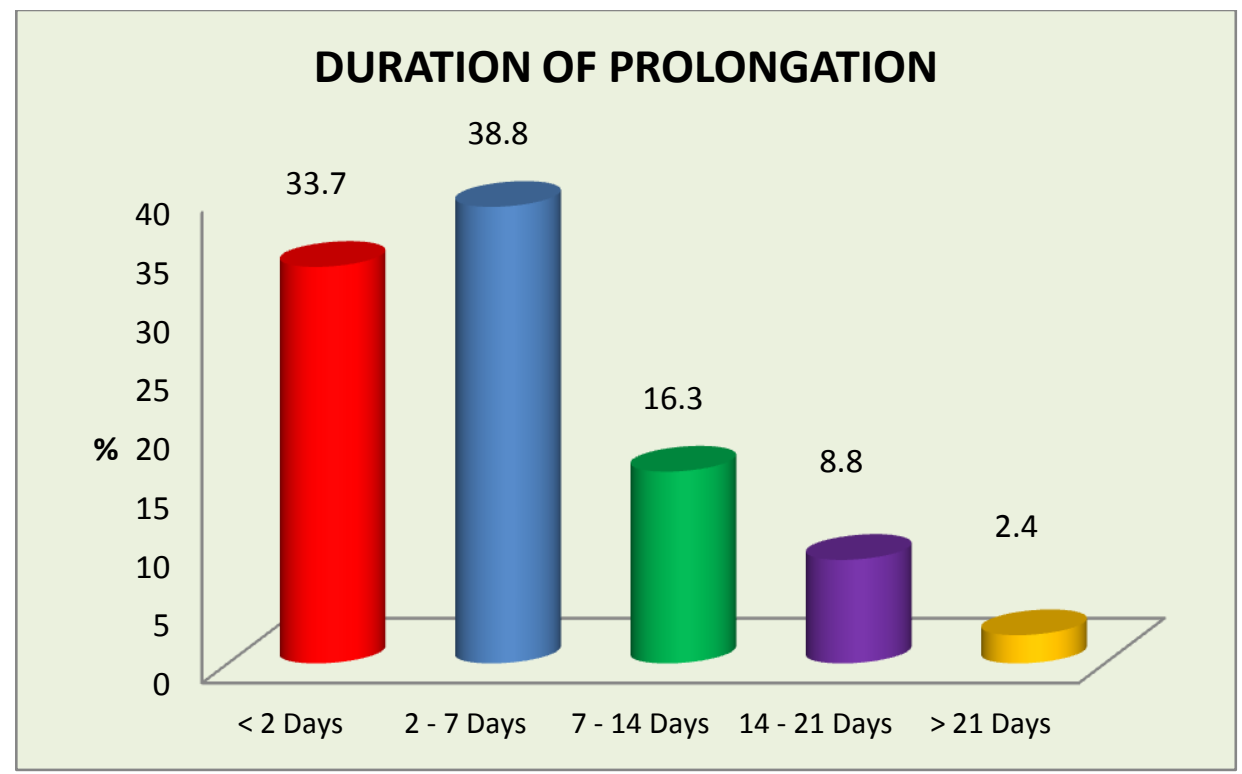

The common duration of prolongation was 2 to 7 days in which $38.8 \%(\mathrm{~N}=31)$ was observed prolongation of less than 2 days was observed in $33.7 \%(\mathrm{~N}=27)$ prolongation was 7 to 14 days for
$16.3 \%(\mathrm{~N}=13)$ and $14-21$ days for $8.8 \%$ $(\mathrm{N}=7)$ prolongation of $>21$ days was observed in $2.4 \%(\mathrm{~N}=2)$.

Table: 5 Success Rate of Acute Tololysis

\begin{tabular}{|l|c|c|}
\hline Success Rate & Number & Percentage \\
\hline$<48 \mathrm{hrs}$ & 27 & 33.8 \\
\hline$>48 \mathrm{hrs}$ & 53 & 66.2 \\
\hline Total & 80 & 100 \\
\hline
\end{tabular}

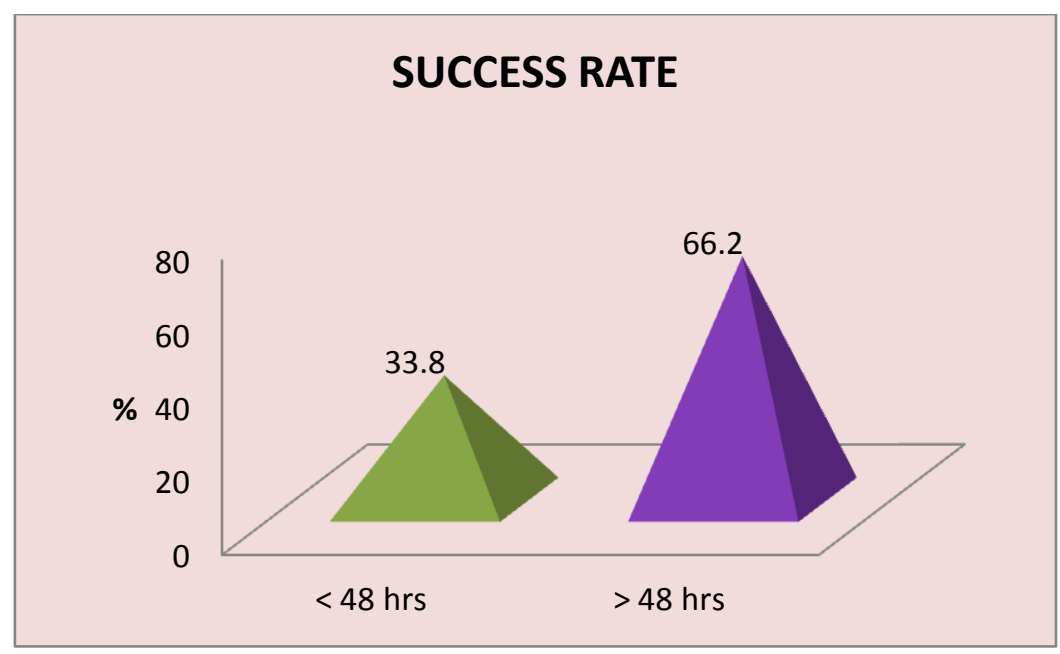

The success of acute tocolysis was $66.2 \%(\mathrm{~N}=53)$ 
Table: 6 Prolongation of Pregnancy

\begin{tabular}{|l|c|c|}
\hline G.A & Number & Percentage \\
\hline$<36$ & 73 & 91.3 \\
\hline$>36$ & 7 & 8.7 \\
\hline Total & 80 & 100 \\
\hline
\end{tabular}

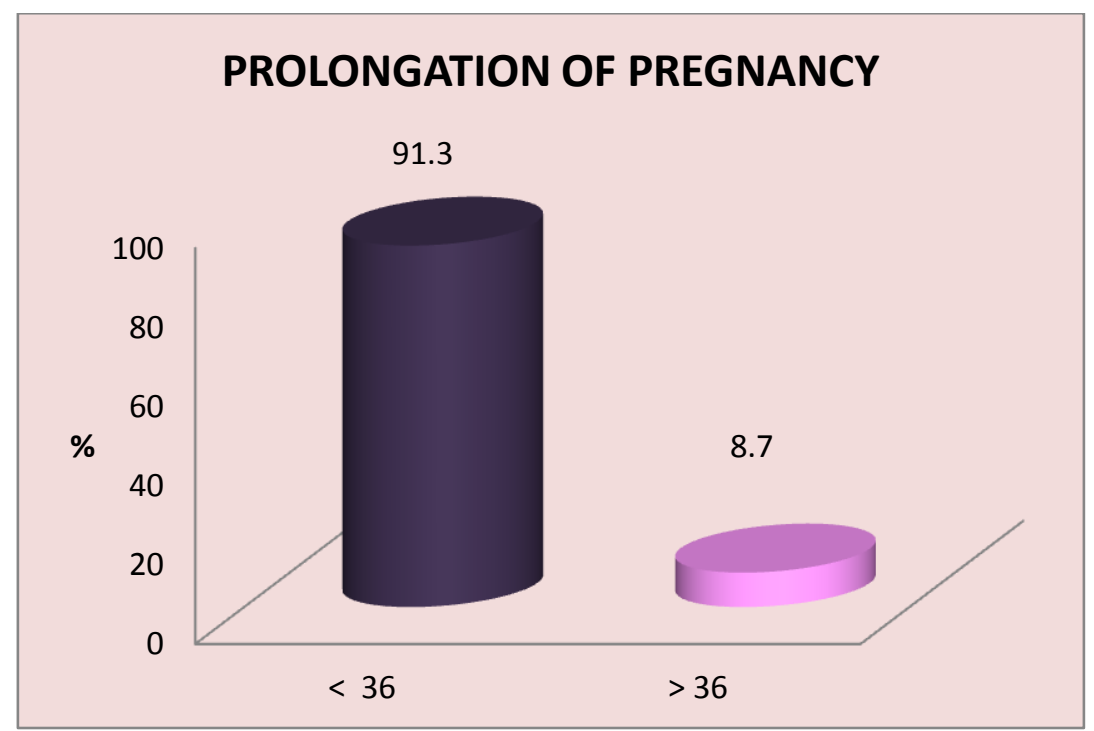

Prolongation of pregnancy for 36 weeks and above was $8.7 \%(\mathrm{~N}=7)$ whereas most of the women had gestational age of $<36$ weeks $(\mathrm{N}=73$, $91.3 \%$ ) at the time of delivery.

\section{Discussion and Summary}

On analysis of data, tocolysis with transdermal nitroglycerine patch is safe with good therapeutic efficacy. ${ }^{6}$

When this data is compared with previous studies, bare line characteristics did not differ significantly. In study by lees et al, multiparous more common than primi, age distribution were 25-29 years. ${ }^{7}$ Gestational age at entry considerably different. In our study patient belongs to gestational age 32-34 weeks.

Cervical dilation ranges from $2-3 \mathrm{~cm}$ whereas in study by Rowland's (1996), cervical dilation ranged between $2-8 \mathrm{~cm}$. Cervical dilatation infound much on prolongation of pregnancy. When cervix is $>2 \mathrm{~cm}$ dilated tocolysis efficacy is minimal.

In lees et al (1994) study main side effect of NTG patch was headache (30\%), in our study (21.3)

Success rate of tocolysis was $95 \%$ in lees et al (1996) but in our study success rate was $66.2 \%$.
NTG patchis considered to be safer drug for its ease of use, easy metabolism, with no side effects besides headache. ${ }^{8}$

While efficacy was studied, transdermal NTG patch act as good acute tocolysis, till the action of steroid and provide time for the transfer of mother to tertiary neonatal care unit. ${ }^{9}$

Also economic evaluation of trial was done. ${ }^{10}$ Both cost and consequence of treatment with nitroglycerine was evaluated. Though NTG patch was costly, but compared to patient course in neonatal unit and stay in hospital, it is cost effective. $^{12}$

NTG patch delay preterm delivery rate ${ }^{11}$, acute tocolysis efficacy, very minimal side effect and good outcome in babies makes the drug superior to other tocolysis

\section{Reference}

1. Martin DH, et al., double blinded placebo controlled treatment trial of Chlamydia trachomatis endo cervical infection in pregnant woman. Infect dis obst gynec, 1997; 5:10.

2. Klein Jo, Braun P and Lee YH et al., Birth weight and genital mycoplasma in 
pregnancy. N Eng J Med., 1971; 284:167171.

3. Benito $\mathrm{CW}$ and Blusewicz TA. The relationship of ureaplasma urealyticum cervical colonization and preterm delivery in high risk pregnancies obstet gynecol.

4. Edwards LE, Barrada MI, Hamann AA and Hakanson EV: Gonorrhea in pregnancy, AJOG, 1978; 132:637-641.

5. Fuch AR-oxytocin receptors in the human uterus during pregnancy and parturition, AJOG, 1984; 150:734.

6. Arias F. Pharmacology of oxytocin \& Prostaglandins, Clinical obstet gynecol, 2000; 43:455-68.

7. Cox SM, King MR, Casey ML and Mac Donald PC: Interleukin 1, -1and -6 and Prostaglandins in vaginal and cervical fluids of pregnant women before and during labour. J Clin Endocrinol metab, 1993; 77:805-815.

8. NIH consensus statement: Effect of corticosteroids for fetal maturation and perinatal outcomes, Vol.12, No.2, Bethesda National Institute of Health, 1994.

9. Tocolytic drugs for women in preterm labor RCOG clinical Guidelines no.1 (B), October, 2002.

10. Johnson JWC, Austin KL and Jones GS, et al. Efficacy of 17 Alpha Hydroxyprogesterone caproate in the prevention of premature labor. $N$ Engl $J$ Med, 1975; 293:675.

11. Steer CM, Petric RH. A comparison of Magnesium sulfate and alcohol for the prevention of premature labor, AJOG, 1977; 129:1.

12. Canadian Preterm Labor Investigations group treatment of preterm labor with beta adrenergic agonist ritodrine, $N$ Engl $\mathrm{J}$ Med, 1992; 327:308.

13. Weristorm K, Weiner CP and Merrill D et al. A placebo controlled randomized trial of the terbutaline pump for prevention of preterm delivery, Am J Perinatol, 1997; $14: 87$.

14. Elliott JP. Magnesium sulfate as a tocolytic agent, AJOG, 1983; 147: 277.

15. Muench MV, Baschat AA and Kopelman $\mathrm{J}$, et al. Indomethacin therapy initiated before 24 weeks of gestation for the prevention of preterm birth obstet Gynecol, 2003; 101:655. 